\title{
REVERBERATION AS MIMETIC REPLICATION: URBAN SPACE, METRO BUSKERS AND ACOUSTIC EXPERIENCE
}

\author{
NICK WEES \\ CENTRE FOR THE STUDY OF THEORY AND CRITICISM, \\ UNIVERSITY OF WESTERN ONTARIO
}

This article examines the essential role of reverberation in everyday spatial experience and argues that the perception and production of reverberation - along with the related concept of resonance - is an example of an innate mimetic capacity residing in both living beings and seemingly inert matter. Reverberation, and acoustic experience more generally, are explored in relation to urban space, with attention paid to the transformation of sense experience in modernity. Drawing on a range of authors, with reference to the work of Walter Benjamin in particular, this article proceeds from a primarily theoretical level to that of concrete human experience, with the example of buskers (street musicians) who perform in the highly reverberant spaces of Montreal's underground metro system. Drawing on the author's ethnographic research among metro musicians, this article demonstrates that reverberation is a vital element in busker practices and experience, and argues that, in their practices and in their effects on space and passersby, metro buskers make evident - make perceptible - the mimetically reverberant relations between body and space, and between self and other.

KEYW ORD S : reverberation; resonance; mimesis; acoustic perception; busker; metro musician; architectural acoustics; urban space.

In these pages, I examine the production and effects of reverberation, as a theoretical concept and a component of acoustic experience, and connect this aspect of the urban sonic environment to the concept of mimesis. I argue that reverberation, a key acoustic element of everyday experience, is a perceptible instantiation of mimetic activity that underscores the inter-relationality of sensing bodies, social and technological practices, and urban architecture. It is my contention that reverberation - and the related concept of resonance - is an expression of a mimetic capacity residing in human actors and seemingly inert materials. That is, in our everyday activities and relations with things and each other, there lies a generative capacity that is reproductive of those activities and relations, but always subject to the singular material-historical conditions under which they unfold. As I will argue, the essential role of reverberation in acoustic experience can be understood as a mimetic propensity by which we both integrate 
and distinguish ourselves relative to our environment. To bridge the territory between the largely theoretical concepts of mimesis and mimetic reverberance, on the one hand, and the lived experience of human actors, on the other, I turn to the example of "buskers" (street musicians) as active participants in the acoustic fabric of urban life who may alter the sensorial trajectories of passersby. While not delving into the science of acoustics, I do discuss the nature of acoustic perception, specifically within reverberant urban spaces. In exploring the concept of mimesis, I have been particularly inspired by the writings of Walter Benjamin. Although my focus is primarily at the theoretical level, I bring the discussion back to the concrete - to the materiality of space and perception - by examining how buskers negotiate and alter the sonically challenging spaces of public transit systems. I make reference to a few other studies of buskers in such settings but draw primarily on my own research among musicians who perform in the stations and underground passageways of the metro system in Montreal, Canada ${ }^{1}$. The mimetically reproductive effects of reverberation in these spaces - varying in intensity and tonal qualities, from place to place - constitute a vital element in busker practices and experience, in how they perform and how they are perceived. In their practices and their effects on the surrounding space and on passersby, metro buskers make evident - perceptible - the mimetically reverberant relations between body and space, and between self and other.

\section{SENSE RELATIONS, ACOUSTIC EXPERIENCE, REVERBERATION}

Benjamin's Arcades Project (1999) details the transition into mature capitalism and the spatial and architectural transformations accompanying and contributing to rapidly changing social and sensorial relations. He describes the increased emphasis on visuality in the new urban centres of commerce, epitomized by specialized fashion stores catering to nascent bourgeois consumerism and, especially, the department store: a new commercial institution where, as Howes notes, "goods were largely out in the open and anyone could enter simply with the purpose of having a look" (2005, 284). Linking the modern sensorium to the economic relations of mature capitalism, Benjamin writes that "with the increase in displays of merchandise... the physiognomy of the commodity emerged more and more distinctly" (1999, 368), suggesting an incipient affinity between the commodity and the visual image as object. Like the fetishized commodity form, which severs its ties to the means and moment of its production,

I From May to September 20I6, I carried out research among Montreal metro buskers, including extensive observation; multiple interviews and casual conversations; audio and video recordings (for the finished videos see https://vimeo.com/wees); and elements of participant observation, including busking on multiple occasions. 
the reified image assumes an independence and mobility, exerting a power of fascination yet lacking any rootedness in lived experience. Much has been made of this preoccupation with the visual image in Benjamin's work; though this provides fruitful avenues of inquiry, too often it is at the neglect of other sensory modes. Indeed, ocularcentric models are common in much of the literature on sense perception, especially in more theoretical or philosophical writings. For example, Merleau-Ponty's influential phenomenology (20I2) works toward an understanding of perception and consciousness that encompasses a full range of bodily sensations, yet tends to rely on and perpetuate visual models and language. However, numerous anthropologists have engaged with and adapted phenomenological approaches, broadening our understanding of sensation, perceptual modes and the role of the emotions in our relations with our environment and each other (e.g. Jackson 2017, Howes and Classen 2014, Stoller 1989). The point is not to invert a hierarchy of the senses or to deny the crucial role of vision in the human sensorium. Rather, focussing on other modes of perception allows for a richer understanding of a range of social phenomena and of the co-constitution of body and space. A critical analysis of sensory modes also helps expose how the senses are ordered and perception structured in a given society. Indeed, as Le Breton argues, "the interrelatedness between human beings and the world depends on the symbolic systems that mediate between them," and that consequently, "the senses... channel [socio-cultural] meaning, creating a particular order and organizing a multitude of information" $(2017,17)$. As a component of the intersubjective relations by which we locate ourselves within the world, acoustic perception involves processes that help organize sensation and enable us to react in accordance with our environment. Attending closely to sonic experience both blurs the boundaries between subject and object and destabilizes sharp distinctions between sensory modes and pathways. Rather than treating sound as a separate domain or assuming the existence of a "soundscape" distinguishable from a (primarily visual) landscape, I concur with Ingold (2007) that our experience of the world "is not sliced up along the lines of the sensory pathways by which we enter into it" (IO) and that sound is neither strictly "mental [or] material, but a phenomenon of experience... of our immersion in, and commingling with, the world in which we find ourselves" (II).

Although we tend to think of sounds as things, as objects, they "are" objects merely in the sense of "that which is perceived - that which is available for attention, thought, and demonstrative reference" (O'Callaghan 2007, I3). Perceived sound results from a transfer of energy that sets in motion vibrations in various elements of our perceptual apparatuses (primarily in the inner ear). These vibrations are "translated" into electrical charges and relayed to the brain, which orders the whole into "hearing sound." A vibrational force has characteristics specific to the physical make-up of its source; these manifest themselves as particular frequencies which produce vibrations in the parts of the body that are "tuned" to those frequencies. Thus, the perceiving apparatus must 
be structured in such a way that it can resonate "in sympathy" with the particular wave frequencies that constitute the perceived sound. This relation of mutual attunement extends into the space in which the sound source and perceptor are located: we are not always aware of it, but what we hear involves more than the "event" we associate with a particular sound. When we hear something, we perceive both the sound-event a voice, a trumpet blast, a passing car - as a vibrational force emanating from the sound source and as a series of reflected energy frequencies that extend from the sound source and bounce off surrounding surfaces before finally reaching us. These secondary sound signals add specific qualities to the perceived sound and "are merged by perception into a single sonic effect: reverberation" (Augoyard and Torgue 2005, III). Though all spaces impart some degree of reverberation, we usually only notice this in certain situations (e.g. the sound inside a cathedral or concrete stairwell, footsteps receding down a long corridor, or hammering echoing off neighbouring houses). The size, shape, and physical make-up of any space impart particular acoustic qualities: reverberation is, thus, central to how we locate ourselves in space (Young 2017). Moreover, even in wide-open outdoor spaces, sound reflects off the ground and other nearby surfaces, though this effect is often below the threshold of conscious perception (Truax 200I, 69). Frequencies that are too weak or beyond the normal range of our hearing (too high- or too low-pitched) can nonetheless be sensed as vibrations, especially in the chest cavity, diaphragm and certain bones in our bodies (Augoyard and Torgue 2005).

While for the blind, reverberation and sound in general are critical for self-location, and for the deaf sound perceived as haptic vibration transmits vital information about the surroundings, most of us only consciously perceive the frequency range to which our ears are accustomed and attuned. Furthermore, music may be felt as resonance literally, as sound waves that are transduced through our nervous-sensory system, and affectively, as movement and force - and can be played by deaf musicians in time and in tune with other musicians, given the requisite vibrational sensitivity. Music as felt rather than simply "heard": here, sense categories blur into each other. The resonant force that we perceive as sound is not bound to hearing, to our ears, quite so firmly. That we detect and process elements of such a vibrational force without our ears is worth highlighting, for it indicates that acoustic perception exceeds the very organ that we designate as the organ of audition. And, it is noteworthy that this appears not to be true of sight and of the eyes. Complete blindness suggests that no information from the visual field is perceptible. Sound is thus not a bounded field nor is its apperception limited to one sensory pathway. Furthermore, hearing cannot be "turned off" the way sight can be by closing one's eyes. Even when not consciously aware of it, we are processing auditory cues that situate us in space; at the same time, we help mould the sonic signature of a given space. Bodies both emit and absorb sound, so that even if sitting quietly, we are still acoustic participants in that space. 
Following Lefebvre, space is understood here as dynamically produced through human activity, while the particularities of a given space set up the conditions of possibility for future activity. The constitution of what Lefebvre calls the "spatial body" acquires its "material character... from space, from the energy that is deployed and put to use there" (1991, 195): a generative relationship between bodies and the environment that supports them and which they continually modify. There is a tension in this spatial production, between a strictly replicative drive to produce the same and a creative impulse that seeks distinction, advantage, difference. The space of play between embodied social beings, architecture, infrastructures and technologies of reproduction can be understood as encompassing a process of correspondences, of mimetic relations. Bodies are formed by space, while space is produced by bodies in motion, by the uses of and claims to space made by embodied beings. There is, thus, a question of a "politics of the sensible" (Laplantine 2015), as the relationships between sense perception and subjectivity involve the broader formation of the senses in a given society and what "counts" as sensible - what Rancière terms "the distribution of the sensible" $(2006)^{2}$. The social mechanisms that accord importance to some ways of sensing and being over others, that impart speech to some but not others, that draw the parameters of what can be said and done, and by whom, produce a sensorium that is reflective of social-material conditions - a sensorium largely "attuned" to conditions at hand. This type of theoretical approach provides an excellent basis for a critical examination of the senses - their history, how they are conceived of, how they operate within socio-material relations, what they "do" and what they "are." Such an analysis questions what can and cannot be sensed, what "is" sensible: what is thought to be perceptible and what "makes sense" (i.e. seems reasonable). However, theoretical-historical analyses fall short if the corporeality of lived experience is left out of the equation.

Our engagement with the world is a fully embodied activity that is inseparable from the social and material practices of a given time and place. Arguing that "thinking, perceiving, remembering and learning have to be studied within the ecological contexts of people's interrelations with their environments" and each other, Ingold write that "it is through the activities of the embodied mind... that social relationships are formed and reformed" (20II, I7I). All human environments have in some respect been inextricably altered by human activity, and the sonic realm of urban space is formed largely by building materials and architectural design. Moreover, "the perception of architecture is spatial before it is visible... we sense space... in a way that differs from our appreciation of pictorial space" (MacArthur 2007, 48I). Sound perception is a vital component in this spatial sense of architecture: as much

2 Le partage du sensible might be variously translated as the "distribution", "partition(ing)" or "dividing/sharing out" of the sensible. 


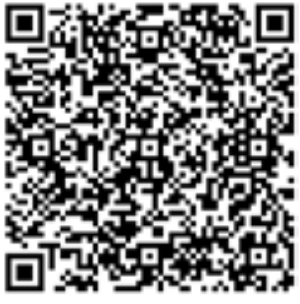

Audio clip 1

as we engage in and with any environment through sight and touch, we do so also by means of acoustic perception, with reverberation playing an essential role. A key point here is that the spatial positioning of both sound source and perceptor (the performer relative to the passerby, in the case of buskers) is central to the qualities of perceived reverberation. This is expressed in Audio clip $\mathrm{I}^{3}$. Two continuous recordings of a song played by a busker, one recorded at close range and the second at some distance, are blended in and out of each other to accentuate the acoustics of that spot located in a long tile-lined corridor.

Sound, speech, and acoustic perception remind us of our intimate, embodied relation with the world. "The sound of the self," writes Truax, "is ultimately entwined with the environment" (200I, 38). If resonance suggests a sympathetic relation between different objects and materials, and between these and living beings, reverberation attests to the fundamental inseparability of sound and space. Because reverberation is integral to everyday acoustic experience, we cannot truly talk about hearing anything independently of the space within which it is heard or as distinct from the acoustic participation of various materials. Indeed, vibrational resonances are not limited to the perceptual apparatus of living organisms but may occur between objects and materials (Augoyard and Torgue 2005, 99ff). For example, the soundboard of a violin resonates in sympathy with, and amplifies, the frequencies set in motion by the string that is plucked or bowed. Simple objects may also be caused to resonate by vibrational forces if the wave frequencies of such forces coincide with the (latent) acoustic properties of the object. An example of such sympathetic vibrations is a tuning fork that is struck, causing it to ring, and is brought near a second one tuned to the same frequency: the vibrational waves from the first tuning fork cause the second one to vibrate and sound (O'Callaghan 2007, 79). The idea of a sympathetic relation between bodies or objects can be understood here as a mimetic capacity, a form of imitative replication. My use of "sympathetic" relates to Frazer's concept of sympathetic magic (1990) in the sense of "having an affinity with", of sharing important characteristics, and the possibility of exerting an influence on seemingly discrete elements via this mutual semblance - not necessarily in the emotive sense of "compassion" or "understanding". However, when it comes to the practices of metro buskers described later in these

3 Audio clip I: Lalo Orozco at Berri-UQAM station

https://rcin.org.pl/Content/I22006/Audio/WA308 152203 P366 Reverberation-as-Mim o00oI.mp3. The first part of this audio excerpt was recorded at a distance of 2 metres from Lalo. At a little less that half-way through, the sound cross--fades into a second recording, made at about is metres distance (Author's recording 20I6). The video from which this section of audio is extracted can be see at: https://vimeo.com/197644517. 
pages, the sociality and intersubjective relations that they conjure can both express and produce vibrations that are sympathetic in more than one sense.

\section{MIMESIS AND THE MODERN URBAN SENSORIUM}

Benjamin contrasts the spatial fragmentation of modernity with the interior domestic spaces of the $19^{\text {th }}$ Century, described as being like a shell that provides comfort and security. Leach writes that this shell-as-dwelling "serves as an inverted mould of the self in which the subject fits snugly, encased like a compass in a velvet covered instrument case" (2OIO, I23), linking architecture with a propensity to both integrate oneself through mimicry and adopt a uniquely subjective position. There is, thus, a mimetic relation between individual and environment: mimesis as the means by which an organism blends into its environment while also distinguishing itself from its surroundings and other, like, organisms - a simultaneous self-effacement and self-identification. In "the concept of mimesis," writes Leach, Benjamin finds "the possibility of forging a link between self and other" and that it is "through the discovery and creation of similarities" that individuals can come to know and understand each other (I24). For Benjamin, the ability to find and produce similarities is being lost: "only minimal residues of the magical correspondences and analogies that were once familiar to ancient peoples" remain $(2007,334)$. However, my claim is that the perception of reverberation is an instantiation of a mimetic propensity that may serve to re-connect the sensing self and the space it inhabits. In over-emphasizing the visual, Benjamin may have underestimated not only the resilience of the human mimetic capacity but also "overlooked" its productive role in acoustic perception. In reverberation - a perceived relation between a sensing being and the space in which it moves - we may locate a mutual attunement between body and world. Moreover, the mobility of participants in this spatial production cannot be underestimated. Moving through space, we gain ever more information, greater spatial awareness, and define a space not only for ourselves but also, to a degree, for other participants in that space (Rodaway 1994). The co-productivity of body and space has been extensively theorized by Lefebvre, whose concept of rhythmanalysis treats the body as the means by which we both gauge and reconfigure the varied rhythms of the lived world (2004). While such rhythms are eminently kinesthetic, they may also be sonic - thus directing us back to reverberation.

Humans have been highly attuned to the effects of reverberation for millennia (Blesser and Salter 2007), but modern technologies have changed our awareness of and responses to spatial acoustics. As Thompson (2012) argues, what counts as "noise" is neither arbitrary or entirely subjective, nor is it historically consistent. Whereas previously, reverberation gave "the acoustic signature of each particular place", this 
changed with the increased volume of rapidly industrializing cities and "reverberation now became just another noise, unnecessary and best eliminated" (II9). The "problem of noise" thus became the concern of architects, technicians and urban designers. Thompson delineates a highly significant aspect of modern techniques employed in the "handling" of reverberation-as-noise: the subordination of spatial reverberation by technological means, which has two moments. The first occurs with the muting of reverberation inside buildings with new sound-absorbing materials, creating "an acoustically efficient environment and... engender[ing] efficient behavior in those who worked within" (2OI2, I2I). This intensifies the uncoupling of sound and space, with architectural interiors sonically divorced from their physical surroundings. The second involves the microphone and sound engineering. With modern recording technologies, sound comes under the mastery of audio technicians who define "what constitute[s] good sound": clear, with minimal reverberation and easily manipulable, sound that "den[ies] the space in which it was produced" (I22). In this account, architectural design and audio recording technologies alter the modern sensorium in such a way that sound seems to cut its ties to the specificities of place and production altogether. In the recording studio, musical instruments are typically recorded "dry"(with the least perceptible reverberation possible) and "artificial" mechanically-generated reverberation of a desired quality is subsequently mixed back in. In Benjaminian terms, the "aura" of sound is thus destroyed. Indeed, Benjamin wrote at length on modern technologies of reproduction, what Taussig terms "mimetically capacious machines" (1993), especially the camera lens and film production, both in terms of the loss of "aura" they cause and their potential for fostering new forms of mimetic activity. It may be, then, that reverberation is a key to somehow redeeming the fragmented sensoria of life under mature capitalism and recuperating sound's actual attachment to the space and means of its production.

My argument, thus far, is that acoustic experience is an often underestimated mode of being, of thinking and doing, of acting in the world; and, that reverberation, as the perception of sonic reflections of sound-events in and through an environment and of ourselves moving in that environment, represents a form of mimetic replication. Repetition of the same but with difference: an impulse toward reproduction that aims for integration into the environment and simultaneously seeks distinction, that aims for self-replication. The mimetic impulse: an insect camouflages itself by mimicking features of its surroundings, avoiding predators, gaining a reproductive advantage; a pedestrian falls into step with the momentum of the crowd, yet is able to exploit small openings in the movements of the mass; sound waves refract through space, bounce back toward each other, like a murmur of voices all saying the same thing but all in different ways. The pulse of the city reproduces the meter and cadence of its inhabitants, of human activity, simultaneously setting the pace for the rhythms of the everyday (Photo I). The periodicity of sound waves is temporal and rhythmic; the 


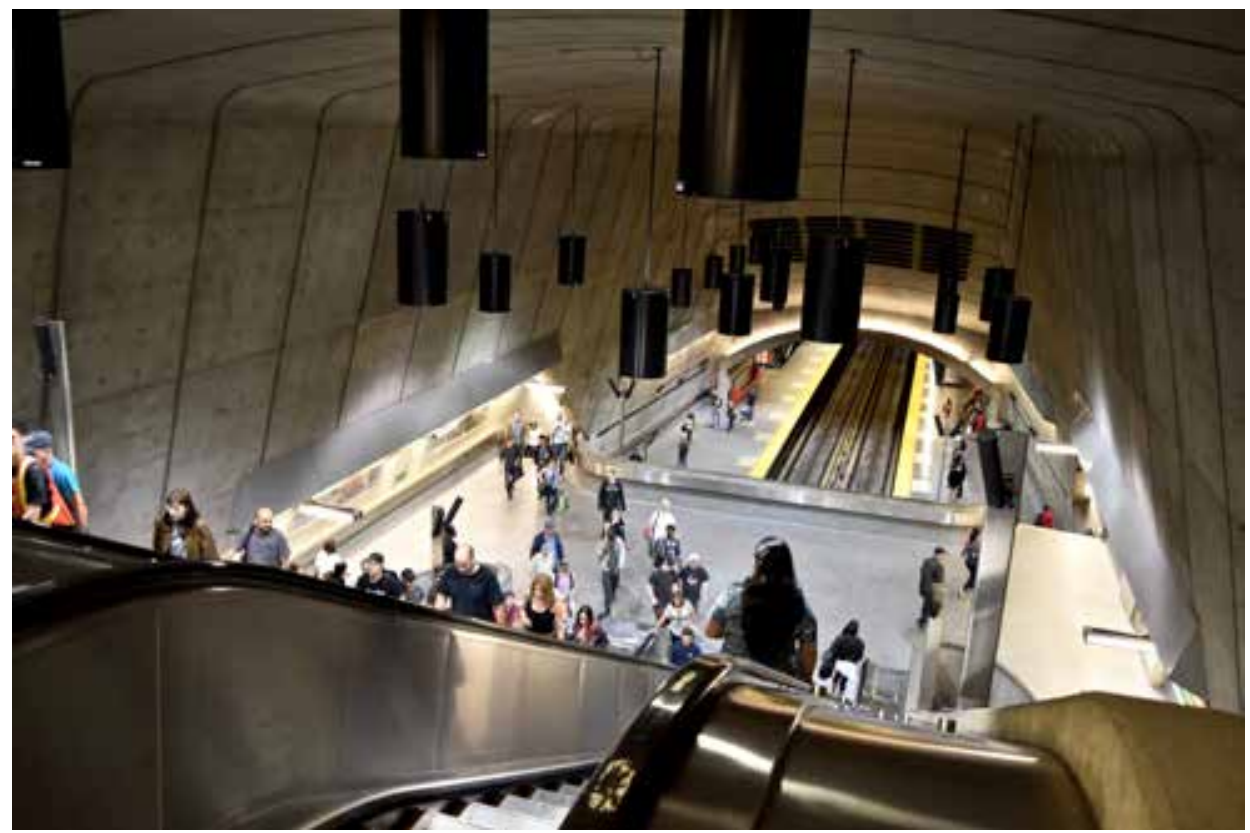

Commuters at Radisson station. Every station in Montreal's underground transit system is uniquely designed and each has its own unique blend of sounds of trains, commuters, rattling escalators, ventilation systems and public service announcements ringing through the reverberant space

(Author's photo, 2016)

perception of reflected sound blending with direct sound from a sound-event involves a mimetic attunement with surrounding space. The resonances of objects and materials, alive or inert, suggest a relationship of sympathetic rhythmicity, while the reverberance of space reveals the co-productivity of perception and environment, of the social and the material, of active bodies and urban architecture.

To concretize this idea of mimetic reverberance as actual and embodied, we will descend into the urban underground. According to Labelle, this is "a reverberant space: cavernous and $\operatorname{dim} . .$. echo[ing] with sounds and voices," and due to its "acoustical conditioning the underground provides a key geographic coordinate for acousmatic experience" (20IO, 4). For Labelle, underground acoustics are pre-eminently characterized by a reverberance that accentuates some sounds while blurring others, creating a muddied acoustical space that disorients, perhaps even oppresses. However, my concern is less with the acousmatic experience of "reduced listening" than with how reverberation may reconnect us to our surroundings. Reduced listening, according to Chion, refers to a "listening mode that focusses on the traits of the sound itself, 
independent of its cause and its meaning" (2OI2, 50) - a sort of acoustical phenomenological reduction. The goal is to focus purely on the specific qualities of a sound. While this can be a productive activity, "opening up our ears and sharpening our power of listening" (5I), it is one that deliberately attempts to sever sound from the conditions of its production. This approach tends to reinforce the fragmentation of sense perception with the reified sound-image becoming a free-floating object, as divorced from the world of grounded sensual experience as is the fetishized commodity form. My goal lies in the opposite direction: an attempt to reintegrate perceived sound into the socially and materially emplaced experience of the perceiver, into the subjectivity of singular experience. In point of fact, Labelle does situate his account of underground acoustics within the broader social realm, drawing on film, literature and historical accounts, some of which provide compelling instances of sound as experiential. Yet, in many discussions of sense perception and its relationship with dominant socio-political and material-economic structures, insightful as they may be, there appears to be a lacuna; something seems to be missing. What is in fact missing, or erased by the imposition of an abstract and universalized "type", is the body as a living being, as a relational subjectivity that is always materially and socially located, - not The Body writ large, but bodies: gendered, classed, racialized, performed, linguistically enacted, but always and firstly sensed, lived. And, it is precisely the in-depth, experiential ethnographic account that is best able to address the lack of plurality and difference, the erasure of singular subjectivities in much theorizing of the human sensorium. As Laplantine notes, ethnography is concerned not with generalities but is "the method of the infinitely small, of attention to small details and details of details" (2015, 47).

\section{UNDERGROUND RESONANCES: METRO BUSKERS}

I have described elsewhere the musical and spatial practices of metro buskers, arguing that the "busker type" - what constitutes $a$ busker - is, in fact, not a type. Irreducible to a simple classificatory definition of "profession, identity or bounded subject-position," the activity of busking must "be understood as an assemblage-act, involving multiple participants - human and material - that emerges through the practices and creative tactics of an individual performer" (Wees 20I7). As an ensemble of practices, busking is always relational, embodied, temporally and materially transient. Given the extremely varied motivations and self-conceptions of buskers, as well as the details of what and how they perform (including instrumentation, repertoire, whether amplification and/or recorded accompaniment is used, how they position themselves and engage, or not, with passersby) and how all of these are tied to personal trajectories and wider historical currents, it is impossible to accurately describe what busking is without reference to the material and social conditions within which these 
practices unfold. Furthermore, busking - particularly in the subterranean spaces of the metro - demonstrates how reverberation situates us within an environment, as well as how acoustic experience offers an avenue for creative action and tactical appropriations of public and semi-public spaces.

In his description of the Paris metro, Augé (1986) treats this subterranean space as separate and distinct from the city itself - a sort of heterotopic space, where chance encounters and the unexpected brush up against the habitual trajectories of commuters. Yet, at the same time, he sees the metro as integral to the city as a whole, creating direct correspondences between locales that, at surface level, appear far-removed from each other; it is an under-world of memory and displaced sense, defined above all by movement. In her study of Paris metro musicians, Green (1998) links the temporality of the metro - a key characteristic of such spaces - with that of music. Thus, an apparent affinity exists from the outset between live musical performance and the liminal spaces of the metro. As does Green with respect to the Paris metro, Tanenbaum (1995) qualifies the spatial acoustics of the New York subway as reverberant and sonically cluttered. For some musicians this creates difficulties, with their music becoming muddied or lost in the noisy cavernous spaces, but for others the pervasive reverberance can be a boon, adding warmth and depth to their sound. A busker who performs in Grand Central Terminal extolls the acoustics there, telling Tanenbaum that he knows the musical key to which that space is tuned (1995, I5). Similarly, in my own research in Montreal, some metro musicians complained about the echoey and generally loud atmosphere at some of the performance sites, while others said that the reverberant character of certain spots enhances the overall quality of their sound. A professionally-trained percussionist playing steel drums (or "steel pan") says that the acoustics in the metro are ideal for his instrument: the reverberance adds warmth, while the bright sound of the "pans" cuts through the sonic murkiness of the station. Indeed, even from afar his instrument is clearly heard above the general din of trains and passersby (Photo 2 and Audio Clip 2) ${ }^{4}$. Similarly, a trumpet-player says he knows that he can be heard clearly on the train platform below, and up above near the street-level exit: he is halfway between, in a wide hall where several corridors converge. The sound of the trumpet resonates through the station, making audible the underground architecture.

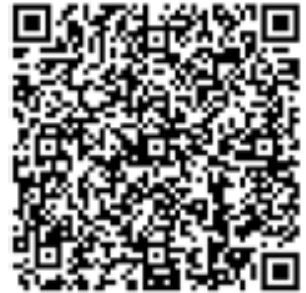

Audio clip 2

4 Audio clip 2: A recording of Joseph playing steel pan, from a distance: the spatial reverberation is perceptible (Author's recording 20I6).

https://rcin.org.pl/Content/I22006/Audio/WA308 I52203 P366 Reverberation-as-Mim 00002.mp3.

The entire video from which this section of audio is extracted can be see at:

https://vimeo.com/202567140. 


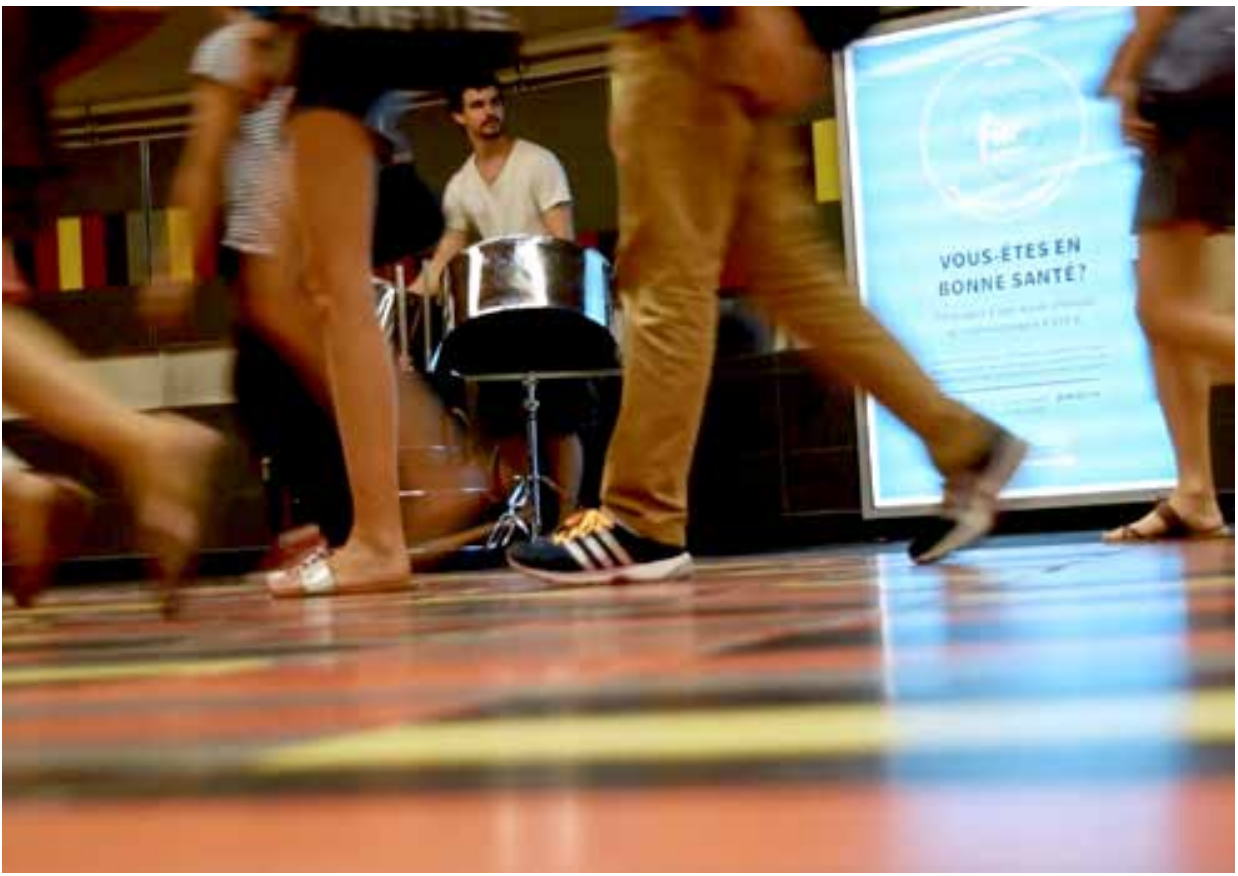

Joseph at Guy-Concordia station. Despite his proximity to the train platform, the bright sound of the "steel pan" is clearly audible through the rush of passing commuters (Author's photo, 2016)

Some musicians feel that the acoustics of certain busking spots suit them better than others - largely a function of their instrument(s) and musical style, with one busker saying that what is most important is if the music is a "good fit" for that spot. The most popular spots typically combine good exposure to passersby with enough space to set out a case, hat or other receptacle for donations ("tips" in the words of several interviewees), and what these enterprising musicians consider to be good sound: not too "noisy", with some attention paid to the reverberance of the spot. The spaces where these spots are located are built of hard, sonically-reflective materials: concrete, brick, tile, steel, plate glass. They are varied in shape and dimensions: long corridors, wide platforms at the juncture of stairs and escalators connecting different levels, cavernous concourses where the murmur and rush of commuters marks the daily rhythms of the city. Materials and infrastructures show themselves to be active participants in the resonances of the underground. Aside from the level and tonalities of the spatial reverberation, noise is an important consideration for musicians: trains arriving and departing, announcements on the public address system, rattling escalators, ventilation systems and, of course, the footsteps and voices of passersby, who may surge 
past in great masses during rush hours (Audio Clip 3) ${ }^{5}$. Some musicians seek out quieter spots, but for those who use electrical amplification, it is easier to adjust to the varied conditions of different spots. However, this can involve more than simply adjusting the volume by turning a knob.

One musician says that at one of his favourite spots he turns his amplifier to face the wall directly behind him, otherwise the sound bounces off the opposite wall about five meters in front, sonically oversaturating the narrow

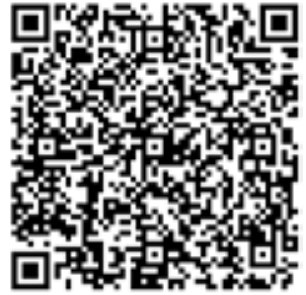

Audio clip 3 space; but, if he simply turns down the volume, he gets drowned out when a crowd filled with many voices passes by. Another electric guitarist talks about the dominant frequencies at different spots: low-end bass frequencies tend to dominate in long corridors constructed of tile and brick, whereas in a more open spot, high frequencies come to the fore. To compensate, he makes tone adjustments on his guitar and amplifier. Moreover, in addition to volume and tonal modifications, some buskers are cognizant of the rhythms in the underground; indeed, some musicians will play in time with the pace of passersby. "Watch the timing of people's footsteps as they walk by", I was told, "and then you play to that beat." The idea is that if the music is "synced" with passersby, they will "connect" with it and will respond more - a form of sympathetic rhythmicity, perhaps. This explanation from an experienced busker exhibits a creative and relational understanding of busking practices, suggesting a certain rhythmanalytical sensitivity that performers may develop. Indeed, this practice-based theorizing derived from pragmatic experience may be taken as an affirmative reply to Lefebvre when he asks: "Is there an instinct of rhythm?" (2004, 64). While most of the rhythmic synchronizing in our daily lives operates at a barely conscious level, it is possible also to "read" the various rhythms in a given setting, working with these to both integrate oneself into, and distinguish oneself from, the surrounding environment - a mimetic correspondence with reverberant space. The performer must "sound good" in that spot, must blend in to a degree, but must also stand out, capture and hold the attention of passersby, if only fleetingly. These few examples illustrate musicians' creative engagement with the spaces of the metro and their attempts to adjust to and play with those spaces' reverberation and rhythmic structures, revealing a dynamic constructionist understanding of space on the part of many metro musicians. Whether by mimicking movement or sensing architectural resonances and

5 Audio clip 3:

https://rcin.org.pl/Content/I22006/Audio/WA308 I52203 P366 Reverberation-as-Mim 00003.mp3.

The footsteps and voices of a multitude of passersby resonate through a long corridor at BerriUQAM station as the drifting sound of a saxophone plays out a familiar refrain, blending into, yet adding its own distinctive voice to, the sonic texture of the metro. 
reacting accordingly, these performers both reproduce the acoustic and spatial characteristics of the metro and alter them, infusing new possibilities into the subterranean sonic realm: metro buskers in mimetic correspondence with passersby and with the architectural acoustics and physical layout of a space.

For some performers, visibility and comfort are at least as important as considerations of sound. Yet, while some give little thought to the acoustics of the performance space, others go to great lengths to work with and against the sonic constraints and affordances of the underground. One professional musician who plays baroque music on the viola performs in the metro largely for the sound. He comments that the acoustics in many of the stations are similar to those of a baroque cathedral, and that a lot of the music he plays was composed for precisely this sort of acoustic environment. Not simply mundane and mute aspects of urban infrastructure, the cavernous stairwells and long open corridors of metro stations resonate with tonal qualities of the past: music and architecture, echoes of human history and creation converge, comingle, reduplicate, reverberate. "An echo", writes Smith, "is nothing if not historical" (2015, 355). Indeed, another form of echoic replication is found in the common busker practice of playing "cover songs". The majority of the musicians I spoke with play only, or at least some, "covers": songs by other musicians, usually well-known pop, rock or folk tunes (by artists such as The Beatles, Neil Young, Bob Dylan, etc.). While the motivation for this can often be financial or simply to "connect" more with passersby (in busker logic, people respond more to what is familiar), the practice constitutes a form of quoting $^{6}$ that references a past event but re-creates it always afresh. Music is never static: it is only perceptible, only exists, in its performance and reception.

By appealing to the past (i.e. the original version of the song) and emotional connections to the past (associations individuals may have with that song), there may be an element of nostalgia implied by the performance of covers (Boetzkes 20IO). However, busker practices and repertoires are much too varied for the nostalgia-tinged playing of covers to be somehow definitional of busking as a whole. Moreover, this appeal to the past may be to an imaginary as much as to an actual past. Tanenbaum argues that while some South American New Yorkers may feel a nostalgia for their homeland and a sense of shared ethnic identity when they hear buskers playing "Andean music", this cultural identity is specifically diasporic and may bear only a partial relation to an actual common regional heritage (I995, 9I). In my fieldwork, I spoke with and observed several Latin American musicians, some of whom play musical instruments and/or styles that are specific to certain regions. I witnessed many instances of cultural recognition, of a shared sense of identity initiated by the music,

6 For an example of the mimetic aspect of quoting in a very different context, see Taussig's argument that the quoting of quoting of quoting (... and so on) characteristic of the Cuna people is a "decisive mimetic component built into Cuna speech" (1993, I09). 
when passersby originally from those cultural regions stopped to talk with musicians. In one case, a woman passing a busker - a recent immigrant from South America, singing in Spanish - stopped and, inspired by the music, sang an unaccompanied Andean folk song, performing for the busker and two other strangers of Andean origin who had stopped to listen. Busker practices, then, include - but are by no means limited to - what might be thought of as nostalgic quoting and inter-cultural citationality (Photo 3). Old forms are renewed, initiating new encounters, new circulations of sociality, with the propagation and diffusion of sympathetic vibrations that may take on an affective quality.

In fact, I was struck by how many musicians see busking as a form of exchange or of gift. Certainly, monetary donations can be an important motivation, but it is not the only nor necessarily the primary one. Indeed, more than a few buskers said that other considerations were more important than money. The most common of these can be summed up, in the words of one musician, as "giving something nice to the public, in a place that isn't very nice," that is dirty, loud and often thought of as

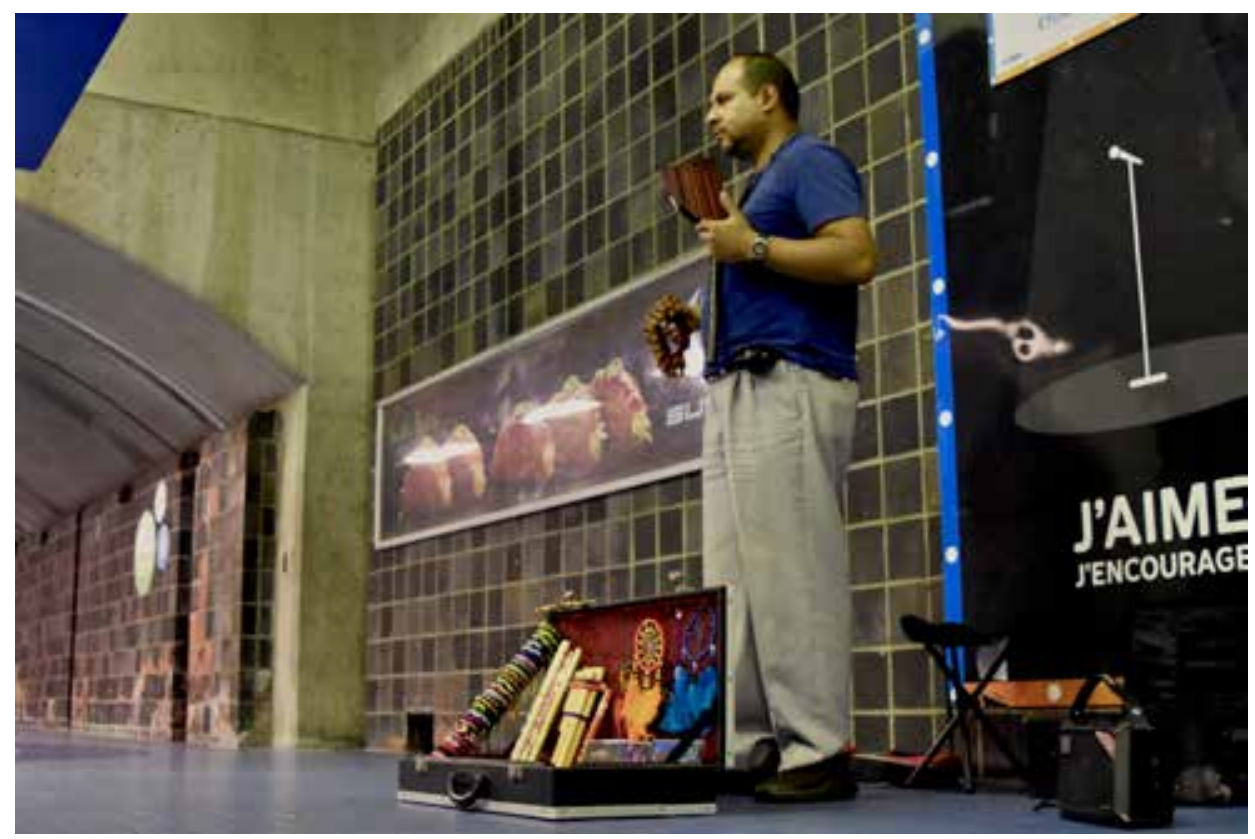

William at Jean-Talon station. He plays traditional Andean instruments but includes many popular songs, by The Beatles for example, in his repertoire. He sells CDs of himself playing, but says that he usually gives away the flutes, bracelets and other items he makes - seen here in his case. Pre-recorded accompaniment tracks play out of a small speaker. (Author's photo, 20I6). 
inhospitable, if not dehumanizing. Getting a positive reaction, even just a smile or a nod of acknowledgement, is highly valued, signalling an awareness of and concern for social resonances - an inter-personal connectivity that can break through the anonymity of the crowd. "Music touches people", said one seasoned busker, "it's a gift" - echoing Mauss' concept of the gift which initiates circulations of goods that, ultimately, create and maintain wider social networks (1967). Busking and gift come together as an inter-personal encounter mediated by and through music: the production and circulation of sympathetic vibrations resonate through people and things, making space and duration sensible - a creative appropriation and re-enchantment of everyday urban space.

\section{CONCLUSION}

Sound and movement, space and sensation are processual relations which are in every instance temporal, transitory, grasped but ephemerally. Likewise, "the perception of similarity is in every case bound to an instantaneous flash," writes Benjamin; "it slips past, can possibly be regained, but really cannot be held fast" (Benjamin and Tarnowski 1979, 66). Surely such a description can be applied to the perception of reverberation. For if the visual image lends itself to a quasi-permanence, a durability and transpos-ability, even if this is largely illusory, the apperception of reverberant space can be but fleeting, as time-bound as it is space-bound. This presents a challenge to the ethnographer who would include the experience of reverberation in the study of a given cultural setting or practice, as we generally have a limited awareness of reverberance and its effects on us as well as of how we ourselves modify the acoustics of a space. Yet, to not account for this would be to ignore an essential aspect of sense perception, of our emplacement in the world, and of our relations with others and with the material infrastructures of everyday life.

It is beyond the scope of this article to detail specific techniques, tools, and analytical frameworks that may be of service in working toward an anthropology of reverberance. However, models that may be productively adopted do exist in ethnographic work on sound and on the senses in general (e.g. Feld and Brenneis 2004, Helmreich 20I2, Imai 2008), and in particular on the creative and critical uses of audio and audio-visual recording and editing (e.g. Boudreault-Fournier 20I7, Pink 2009). Moreover, as I have argued, despite the oft-subtle effects of reverberation, we possess an innate mimetic attunement with our surroundings that provides a degree of access to the production and effects of reverberation, of the mutual resonances between bodies and between body and environment. We possess a sensory awareness of the multiple rhythms and resonances that (in)form us and that are transformed by our activities: though largely a pre-conscious sensing, it can be brought to the level of 
conscious awareness though critical, focussed attention. A "subject-centred" ethnographic approach makes sense here, particularly as the perception of sound (and the more specific experience of musical perception), though mediated by social processes and material realities, is a fundamentally subjective experience (Rice 2003). Participant observation, the core of ethnography, provides a bridge into the individual subjective experiences of those whom we wish to learn from and with, and this entails a fully sensorial engagement. In my research among metro musicians, I busked (guitar and vocals) on numerous occasions at different spots in the metro, allowing me to reflect on the perception and effects of reverberation from the position of the performer. In this way, we may look to, and learn from, the pragmatic everyday understandings that research participants have of acoustic experience and sense perception more generally. Indeed, many metro buskers, in the ways that they creatively work with challenging spatial acoustics, exemplify a practical, localized knowledge, becoming everyday practitioners of urban rhythmanalysis, and savvy readers and manipulators of mimetic relations. Just as ethnography can function as an engaged theoretical-practical activity, a detailed analysis of acoustic experience can unite critical academic understandings with the applied know-how of our everyday lifeworlds.

As I have shown, reverberation is an embodied perception of the relationality of space, of our own presence and of that of others, and, as such, is an instantiation of an innate mimetic capacity present in living beings and seemingly inert matter. Mimetic reverberance may be thought of as a sensed intersubjective awareness of self and other, with the vital participation of objects and architecture, of the materiality of the city in everyday experience, and as expressing a capacity to reproduce the world both as it is and as different. Whereas the reverberant spaces of the city are continuously modified by all who inhabit and traverse them, buskers can alter the acoustic character of urban space in unique and creative ways, creating and transmitting resonances that flow through the city, precipitating ever new trajectories of social and material circulation.

\section{BIBLIOGRAPHY}

A u g é M. 1986. Un Ethnologue dans le métro. Paris: Hachette.

A u g o y a rd J.-F. and Torgu e H. 2005. Sonic Experience: A Guide to Everyday Sounds. Montreal: McGill-Queen's University Press.

B e n j a m i n W. 1999. The Arcades Project. Cambridge: Harvard University Press.

B en jamin W. 2007. On the mimetic faculty. In P. Demetz, (ed.), Reflections: Essays, Aphorisms, Autobiographical Writings. New York: Schocken Books, 333-336.

B e n j a m in W. and Ta r n ow sk i K. 1979. Doctrine of the similar (1933). New German Critique I7, 65-69.

B le s s e r B. and S a l t e r L.-R. 2007. Spaces Speak, Are You Listening? Experiencing Aural Architecture. Cambridge: MIT Press. 
B o e tzkes A. 20Io. The Ephemeral stage at Lionel Groulx station. In A. Boutros and W. Straw (eds.), Circulation and the City. Montreal: McGill-Queen's University Press, I38-I54.

Boudreault-Fournier A. 20I7. Recording and editing. In D. Elliot and D. Culhane (eds.) A Different Kind of Ethnography: Imaginative Practices and Creative Methodologies. North York: University of Toronto Press, 69-89.

Ch i o n M. 20I2. The Three listening modes. In J. Sterne (ed.), The Sound Studies Reader. London: Routledge, $48-53$.

Fr a z e r J. G. 1990. The Golden Bough, Part I Volume I. London: MacMillan.

Feld S. and Brenneis D. 2004. Doing anthropology in sound. American Ethnologist $3 I(4)$, $46 \mathrm{I}-474$.

G r e e n A.-M. 1998. Musicien de métro: Approche des musiques vivantes. Paris: L'Harmattan.

$\mathrm{Hel} \mathrm{m} \mathrm{r} \mathrm{e} \mathrm{i} \mathrm{ch} \mathrm{S.} \mathrm{20I2.} \mathrm{An} \mathrm{Anthropologist} \mathrm{underwater:} \mathrm{immersive} \mathrm{soundscapes,} \mathrm{submarine} \mathrm{cyborgs} \mathrm{and}$ transductive ethnography. In J. Sterne (ed.), The Sound Studies Reader. London: Routledge, I68-185.

How e s D. 2005. Hyperesthesia, or, the sensual logic of late capitalism. In D. Howes (ed.), Empire of the Senses. Oxford: Berg, 28I-303.

Howe s D. and Cla s s en C. 20I4. Ways of Sensing: Understanding the Senses in Society. New York: Routledge.

I $\mathrm{m}$ a i H. 2008. Senses on the move: multisensory encounters with street vendors in the Japanese urban alleyway roji. Senses \& Society 3(3), 329-338.

In g o ld T. 2007. Against soundscape. In A. Carlyle (ed.), Autumn Leaves: Sound and the Environment in Artistic Practice. Paris: Double Entendre, IO-I3.

In g o ld T. 2oIr. The Perception of the Environment: Essays on Livelihood, Dwelling and Skill. London: Routledge.

J a c k s o n M. 20I7. How Life Worlds Work: Emotionality, Sociality, and the Ambiguity of Being. Chicago: University of Chicago Press.

L a bell e B. 20IO. Acoustic Territories: Sound Culture and Everyday Life. New York: Continuum.

Laplantine F. 2015. The Life of the Senses: Introduction to a Modal Anthropology. London: Bloomsbury.

L e a ch N. 20I0. "Mimesis." In G. Hartoonian (ed.), Walter Benjamin and Architecture. London: Routledge, I23-I35.

Le B r e t o n D. 2017. Sensing the World: An Anthropology of the Senses. London: Bloomsbury.

L e f e b v r e H. 1991. The Production of Space. Maiden: Blackwell.

L e f e bvr e H. 2004. Rhythmanalysis: Space, Time and Everyday Life. London: Continuum.

M a u s M. 1967. The Gift: Forms and Functions of Exchange in Archaic Societies. New York: Norton.

M a c A r th u r J. 2007. Movement and tactility: Benjamin and Wölfflin on imitation in architecture. The Journal of Architecture, I2(5): 477-487.

M e r l e a u-P o n t y M. 20I2. Phenomenology of Perception. London: Routledge.

O' C all a g h a n C. 2007. Sounds: A Philosophical Theory. Oxford: Oxford University Press.

P in k S. 2009. Doing Sensory Ethnography. London: Sage Publications.

R a n c i èr e J. 2006. The Politics of Aesthetics. London: Bloomsbury.

Rice T. 2003. Time, place, and metaphor in musical experience and ethnography. Ethnomusicology 47(2): I5I-179.

Ro d a w a y P. 1994. Sensous Geographies: Body, Sense and Place. London: Routledge.

S m i th M. 20I5. Echo. In D. Novak and M. Sakakeeny (eds.), Key Words in Sound. Durham, Duke University Press, 55-64.

S t o ll e r P. 1989. The Taste of Ethnographic Things: The Senses in Anthropology. Philadelphia: University of Pennsylvania Press. 
Ta n e n b a m S. 1995. Underground Harmonies: Music and Politics in the Subways of New York. Ithaca: Cornell University Press.

Ta u s s ig M. 1993. Mimesis and Alterity: A Particular History of the Senses. New York: Routledge.

Th o m p s o n E. 2012. Sound, modernity and history. In J. Sterne (ed.), The Sound Studies Reader. London: Routledge, II6-I29.

Tr u a x B. 200I. Acoustic Communication. Westport: Ablex Publishing.

We es N. 2017. Improvised performances: urban ethnography and the creative tactics of Montreal's metro buskers. Humanities 6 (3), n.p.

Yo u n g N. 20I7. Hearing spaces. Australasian Journal of Philosophy 95 (2), 242-255.

\section{Author's contact:}

Nick Wees

Centre for the Study of Theory and Criticism

University of Western Ontario

E-mail:nwees@uwo.ca

ORCID : $0000-0002-8129-2572$

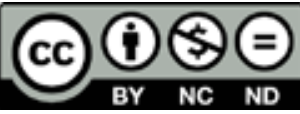


